\title{
Levels of caspase-1 in cerebrospinal fluid of patients with traumatic brain injury: correlation with intracranial pressure and outcome
}

\author{
Jon Pérez-Bárcena, MD, PhD, ${ }^{1}$ Catalina Crespí, PhD, ${ }^{2}$ Guillem Frontera, MD, ${ }^{2}$ \\ Juan Antonio Llompart-Pou, MD, PhD, ${ }^{1}$ Osman Salazar, MD, ${ }^{3}$ Victor Goliney, MD, ${ }^{3}$ \\ Javier Ibáñez, MD, PhD, ${ }^{3}$ M. Ross Bullock, MD, PhD, ${ }^{4}$ and Juan Pablo de Rivero Vaccari, $\mathrm{PhD}^{4}$

\begin{abstract}
${ }^{1}$ Intensive Care Department, ${ }^{2}$ Fundación Instituto de Investigación Sanitaria Islas Baleares (IdISBa), and ${ }^{3}$ Department of Neurological Surgery, Son Espases University Hospital, Palma de Mallorca, Spain; and ${ }^{4}$ The Miami Project to Cure Paralysis,
\end{abstract} \\ Department of Neurological Surgery, University of Miami Miller School of Medicine, Miami, Florida
}

\begin{abstract}
OBJECTIVE The objectives of this study were to evaluate levels of inflammasome-signaling proteins in serum and CSF of patients with traumatic brain injury (TBI), and to correlate these protein levels with intracranial pressure (ICP) and clini-
\end{abstract} cal outcomes at 6 months after injury.

METHODS This is a prospective and observational study in patients with moderate and severe TBI who required an external ventricular drain as part of their treatment. Serum and CSF samples were collected 3 times a day for the first 5 days after TBI. The authors have determined the protein concentration of caspase- 1 in the CSF and serum of patients with TBI by using commercially available enzyme-linked immunosorbent assays. The ICP value was recorded hourly. The 6-month outcome was assessed using the Glasgow Outcome Scale-Extended.

RESULTS A total of 21 patients were included in this study, and a total of 234 paired serum-CSF samples were analyzed. The area under the curve (AUC) value of caspase-1 in CSF during the 5-day period was $2452.9 \mathrm{pg} / \mathrm{mL} \cdot \mathrm{hr}$ in the group of patients with high ICP vs $617.6 \mathrm{pg} / \mathrm{mL} \cdot \mathrm{hr}$ in the patients with low ICP. The differences were mainly on day 2 (19.7 $\mathrm{pg} / \mathrm{mL}$ vs $1.8 \mathrm{pg} / \mathrm{mL} ; p=0.06)$ and day $3(13.9 \mathrm{pg} / \mathrm{mL}$ vs $1 \mathrm{pg} / \mathrm{mL} ; p=0.05)$. The AUC value of caspase in CSF during the 5 -day period was $1918.9 \mathrm{pg} / \mathrm{mL} \cdot \mathrm{hr}$ in the group of patients with poor outcome versus $924.5 \mathrm{pg} / \mathrm{mL} \cdot \mathrm{hr}$ in the patients with good outcome. The protein levels of caspase-1 in CSF were higher in patients with unfavorable outcomes during the first 96 hours after TBI.

CONCLUSIONS In this cohort of patients with TBI who were admitted to the neurosurgical ICU, the inflammasome protein caspase- 1 is increased in the CSF of patients with high ICP, especially on days 2 and 3 after TBI. Also the protein levels of caspase-1 in CSF were higher in patients with poor outcome during the first 96 hours after TBI. Moreover, not only the absolute value of caspase-1 in CSF but also its trend is associated with poor outcomes.

https://thejns.org/doi/abs/10.3171/2020.2.JNS193079

KEYWORDS traumatic brain injury; inflammation; innate immunity; inflammasome; intracranial pressure

$\mathrm{T}$ Raumatic brain injury (TBI) represents an important medical and public health problem across all ages. ${ }^{1}$ These patients are at high risk of death or poor neurological outcomes. This burden of mortality and morbidity demands a comprehensive therapeutic response. ${ }^{1}$ However, despite substantial efforts, we currently do not have any neuroprotective therapy that is effective in the treatment of patients with TBI. ${ }^{1}$
The inflammasome is a multiprotein complex involved in the activation of caspase-1, resulting in an inflammatory response mounted through the processing of the proinflammatory cytokine interleukin (IL) $1 \beta$. We have previously shown that inflammasome proteins are reliable inflammatory biomarkers of brain injury, ${ }^{2}$ stroke, ${ }^{3}$ multiple sclerosis, ${ }^{4}$ and depression. ${ }^{5}$ The relevance of the innate immune system and the inflammasome in the regulation of injury

ABBREVIATIONS ASC = apoptosis-associated speck-like protein containing a caspase recruitment domain; $A U C=$ area under the curve; ELISA = enzyme-linked immunosorbent assay; GCS = Glasgow Coma Scale; GOSE = Glasgow Outcome Scale-Extended; ICP = intracranial pressure; IL = interleukin; NICU = neurosurgical ICU; NLR = nucleotide oligomerization domain-like receptor; TBI = traumatic brain injury.

SUBMITTED November 13, 2019. ACCEPTED February 24, 2020.

INCLUDE WHEN CITING Published online May 1, 2020; DOI: 10.3171/2020.2.JNS193079. 
secondary to TBI has been reported previously by our group and others. ${ }^{6-9}$ Damage-associated molecular patterns (DAMPs) are detected by nucleotide oligomerization domain-like receptors (NLRs), a group of cytosolic pattern receptors that activate the innate immune response. ${ }^{10}$ NLRP1 is an NLR that interacts with caspase-1, which is an apoptosis-associated speck-like protein containing a caspase recruitment domain (ASC), also called an adaptor protein, to form the multiprotein complex named inflammasome. ${ }^{11}$ Activation of the inflammasome leads to cleavage of procaspase-1 into active subunits, which in turn cleave pro-IL1 $\beta$ and pro-IL18 into active forms. ${ }^{3}$

At the experimental level, the inhibition of the inflammasome by means of an antibody results in decreased inflammation and improved outcomes. ${ }^{6,8,12,22}$ Additionally, the inhibition of the NRLP $3^{13}$ inflammasome results in decreased inflammation and improved neurological function. ${ }^{9,12}$ Clinically, inflammasome proteins have been shown to be promising biomarkers of TBI in serum and CSF. Accordingly, low levels of inflammasome proteins such as caspase-1 and ASC in the CSF and serum are consistent with favorable outcomes after TBI. ${ }^{14,15}$

In this study we expand our clinical knowledge about the inflammasome in a group of patients with moderate and severe TBI admitted to the neurosurgical ICU (NICU). The objectives of this study were to quantify acute levels of 2 key inflammasome-signaling proteins, caspase-1 and ASC, in the serum and CSF of patients with TBI, and to analyze the correlation between protein concentration and intracranial pressure (ICP) as well as with clinical outcomes at 6 months post-TBI.

\section{Methods}

\section{Patient Selection}

This was a prospective and observational study in which patients with moderate and severe TBI were recruited in Son Espases University Hospital (Palma de Mallorca, Spain). The Comité Ético de las Islas Baleares approved the study. Written informed consent was obtained from the closest relative according to the IRB protocol. Patients who were included met the following inclusion criteria: severe or moderate head trauma (Glasgow Coma Scale [GCS] score $\leq 13$ ), age $18-80$ years, and ventriculostomy. We did not include any patient with a past medical history relevant to CNS pathology, such as brain tumor, meningitis, cerebral vasculitis, or stroke.

\section{Patient Management}

The patients were admitted at the NICU at Son Espases University Hospital. All patients with moderate and severe TBI received a CT on admission, at 24 hours after hospital admission, and at any time if ICP was uncontrolled. All patients' ICP was monitored using an intraventricular catheter. The treatment of the patients was standardized according to the Brain Trauma Foundation Guidelines. The goal was to maintain the ICP at $\leq 20 \mathrm{~mm} \mathrm{Hg}$. Treatable intracranial hypertension was defined as ICP $>20$ $\mathrm{mm} \mathrm{Hg}$ for $>5$ minutes, in the absence of any external interventions, such as suctioning. Treatment failure was defined when ICP could not be reduced to $\leq 20 \mathrm{~mm} \mathrm{Hg}$ within 20 minutes after treatment intervention was initiated, or a persistent elevation in ICP to $>20 \mathrm{~mm} \mathrm{Hg}$ that required increase in therapeutic intensity level.

The blood pressure was monitored in all patients through an arterial line, and hypotension was avoided using normal saline and/or vasopressor therapy such as norepinephrine. Intracranial hypertension was treated with a stepwise protocol that included head elevation $\left(20^{\circ}-30^{\circ}\right)$; sedation (morphine, midazolam, propofol, or a combination of these); intermittent drainage of CSF; osmotherapy with mannitol, hypertonic saline, or both; and muscle paralysis with cisatracurium. Decompressive craniectomy and/or barbiturates were optional therapies used in refractory intracranial hypertension.

\section{Sample Collection and Analysis}

Serum and CSF samples were collected as soon as possible after the TBI and then collected 3 times per day for the first 5 days. Once the samples were obtained, they were immediately centrifuged at $2000 \mathrm{~g}$ for 10 minutes at $4^{\circ} \mathrm{C}$ to pellet cellular bodies and debris. Then the samples were frozen at $-80^{\circ} \mathrm{C}$ until they were analyzed. They were not mixed and were stored independently. We determined the concentration of caspase-1 in CSF and serum by using a commercially available enzyme-linked immunosorbent assay (ELISA) according to the manufacturer's instructions (R\&D Systems). We performed a recovery test to validate use of the test in serum and CSF because the kit was only validated in cell culture supernatants; we obtained an average recovery of $90.8 \%$ for serum and $80.3 \%$ for CSF. The assay sensitivity was $0.68 \mathrm{pg} / \mathrm{mL}$ for caspase-1.

\section{Data Collection}

Patients' clinical data were recorded. The values of ICP, mean arterial pressure, and cerebral perfusion pressure were recorded hourly using the IntelliSpace Critical Care monitoring system (Version J.00.01; Phillips Healthcare).

\section{Statistical Analysis}

Clinical characteristics of patients and the levels of the inflammasome proteins caspase-1 and ASC were described using the mean and standard deviation, median and interquartile range, or proportions with $95 \%$ confidence intervals, as appropriate.

Because the severity of the initial injury will significantly determine the final outcome of the patient, regardless of any treatment, the results of this study have been analyzed using the "sliding dichotomy" approach. According to this analysis, patients with a less severe initial injury should have a better recovery than those with a severe initial injury. For example, a moderate disability in a patient for whom no better than death or severe disability could be expected is considered a good outcome and, vice versa, we would consider a moderate disability in a patient with an excellent initial prognosis as a poor outcome. As previously described, ${ }^{16}$ patients with a severe initial injury (a GCS score of 4-5 or a GCS motor score of 2-3) were considered to have a favorable outcome if the 6-month Glasgow Outcome Scale-Extended (GOSE) score was 3 
TABLE 1. Summary of demographic data in 21 patients with TBI

\begin{tabular}{|c|c|c|c|c|c|c|c|c|c|c|c|}
\hline $\begin{array}{l}\text { Case } \\
\text { No. }\end{array}$ & $\begin{array}{c}\text { Age (yrs), } \\
\text { Sex }\end{array}$ & $\begin{array}{l}\text { Mech of } \\
\text { Injury }\end{array}$ & ISS & $\begin{array}{l}\text { Time to } \\
\text { Samp } 1\end{array}$ & Samples & $\begin{array}{l}\text { GCS } \\
\text { Score }\end{array}$ & $\begin{array}{l}\text { Motor } \\
\text { Score }\end{array}$ & $\begin{array}{l}\text { High } \\
\text { ICP }\end{array}$ & Surg & $\begin{array}{l}\text { GOSE } \\
\text { Score }\end{array}$ & Intracranial Pathology \\
\hline 1 & $45, M$ & Fall & 25 & $18 \mathrm{hrs}$ & 14 & 7 & 5 & Yes & No & 1 & SDH; diffuse SAH; rt frontal contusion \\
\hline 2 & $22, \mathrm{M}$ & Assault & 25 & $47 \mathrm{hrs}$ & 18 & 13 & 5 & Yes & Yes & 5 & Lt SDH \\
\hline 3 & $30, \mathrm{M}$ & MVA & 50 & $6 \mathrm{hrs}$ & 26 & 3 & 1 & Yes & No & 1 & DAl; brainstem contusions \\
\hline 4 & $53, \mathrm{M}$ & Fall & 25 & $22 \mathrm{hrs}$ & 14 & 10 & 5 & Yes & Yes & 3 & Frontotemporal rt contusions; diffuse SAH \\
\hline 5 & $66, \mathrm{~F}$ & Fall & 25 & $40 \mathrm{hrs}$ & 20 & 7 & 5 & Yes & Yes & 7 & Rt temporal hematoma \\
\hline 6 & $57, \mathrm{M}$ & MVA & 31 & $36 \mathrm{hrs}$ & 26 & 7 & 5 & Yes & Yes & 3 & Rt frontotemporal contusion \\
\hline 7 & $73, \mathrm{M}$ & MVA & 25 & $8 \mathrm{hrs}$ & 26 & 8 & 5 & No & No & 5 & Diffuse SAH; SDH \\
\hline 8 & $27, \mathrm{M}$ & MVA & 34 & $24 \mathrm{hrs}$ & 24 & 3 & 1 & Yes & No & 1 & Brain swelling; basal ganglia hemorrhagic contusions \\
\hline 9 & $47, \mathrm{M}$ & Fall & 41 & $20 \mathrm{hrs}$ & 26 & 3 & 1 & Yes & No & 1 & Brain swelling; It SDH \\
\hline 10 & $66, \mathrm{M}$ & Fall & 25 & $8 \mathrm{hrs}$ & 22 & 12 & 5 & No & No & 8 & Lt frontotemporal contusion; SAH \\
\hline 11 & $67, \mathrm{~F}$ & MVA & 32 & $8 \mathrm{hrs}$ & 28 & 12 & 5 & No & No & 3 & Diffuse SAH \\
\hline 12 & $67, \mathrm{~F}$ & Fall & 47 & $6 \mathrm{hrs}$ & 28 & 12 & 5 & No & No & 3 & Rt frontal SDH; bifrontal contusions; SAH \\
\hline 13 & $64, \mathrm{M}$ & Fall & 25 & $14 \mathrm{hrs}$ & 14 & 11 & 5 & No & Yes & 1 & SDH; rt temporal hematoma \\
\hline 14 & $71, \mathrm{M}$ & Fall & 66 & $9 \mathrm{hrs}$ & 26 & 8 & 5 & Yes & Yes & 1 & Lt temporal hematoma \\
\hline 15 & $32, \mathrm{~F}$ & Sports injury & 25 & $18 \mathrm{hrs}$ & 6 & 6 & 4 & Yes & Yes & 4 & Lt frontotemporal contusions; SAH \\
\hline 16 & $29, \mathrm{M}$ & MVA & 25 & $5 \mathrm{hrs}$ & 26 & 12 & 5 & Yes & No & 1 & Bifrontal hematomas; CC hematoma \\
\hline 17 & $74, \mathrm{~F}$ & Fall & 25 & $24 \mathrm{hrs}$ & 20 & 7 & 5 & Yes & No & 1 & Lt temporal contusion; SAH \\
\hline 18 & $63, \mathrm{M}$ & Fall & 25 & $6 \mathrm{hrs}$ & 30 & 12 & 5 & Yes & No & 1 & Basal bifrontal contusions; brainstem contusion; $\mathrm{SAH}$ \\
\hline 19 & $76, \mathrm{M}$ & MVA & 16 & $6 \mathrm{hrs}$ & 28 & 7 & 5 & No & No & 5 & Parasagittal It frontal hematoma; $\mathrm{SAH}$ \\
\hline 20 & $80, \mathrm{M}$ & MVA & 16 & $14 \mathrm{hrs}$ & 18 & 6 & 4 & No & No & 1 & Bilat SDH; SAH; basal bifrontal contusions \\
\hline 21 & $57, \mathrm{~F}$ & Fall & 25 & $16 \mathrm{hrs}$ & 28 & 9 & 4 & Yes & Yes & 1 & SDH; brain swelling \\
\hline
\end{tabular}

$\mathrm{CC}=$ corpus callosum; DAI = diffuse axonal injury; ISS = Injury Severity Score; mech = mechanism; MVA = motor vehicle accident; SAH = subarachnoid hemorrhage; samples = total number of serum and CSF samples analyzed per patient; SDH = subdural hematoma; surg = craniotomy performed; time to samp $1=$ time from injury to first sample.

or higher. Patients with a moderate to severe initial injury (GCS score of 6-8 or GCS motor score of 4-5) were considered to have a favorable outcome if the 6-month GOSE score was 5 or higher, and those with a moderate initial injury (GCS score of 9-13) were considered to have a favorable outcome if the 6-month GOSE score was 7 or higher. ${ }^{16}$ In this sliding dichotomy approach, the GOSE was dichotomized for analysis into favorable (GOSE score 5-8) and unfavorable (GOSE 1-4) outcomes due to small sample size. Moreover, to analyze the values of caspase-1 in CSF and serum over time, we calculated the area under the curve (AUC) in patients with favorable versus unfavorable outcomes as well as high ICP versus low ICP. To obtain a daily caspase-1 value, we calculated the median of 3 samples in each patient and compared daily values between groups (favorable vs unfavorable outcomes and high ICP vs low ICP), and we used the Mann-Whitney U-test for unpaired tests, with Bonferroni correction for multiple comparisons. A p value $\leq 0.05$ was accepted as significant. Statistical analyses were conducted using SPSS (v18.0, SPSS Inc.).

\section{Results}

\section{Patients and Sample Analysis}

Patient demographic data are shown in Table 1. A total of 21 patients were included; 15 were male and 6 were female. The mean age was 48 years (range $22-80$ years).
The median time to collect the first sample was 14 hours (range 5-47 hours) after TBI. We analyzed 234 paired serum-CSF samples. For ASC measurements, only 24 serum samples from the total of 234 were above the limit of detection of the assay, as were only 26 samples for CSF measurements. For caspase-1, all 234 serum samples were above the limit of detection, as were 175 of the CSF samples. For this reason we focused our analysis on caspase-1.

\section{Caspase-1 Protein Levels Correlate With ICP in the CSF of Patients With TBI}

In this cohort of patients with TBI who were admitted to the NICU, 14 patients presented with high ICP. The AUC value of caspase in CSF during the 5-day period was $2452.9 \mathrm{pg} / \mathrm{mL} \cdot \mathrm{hr}$ in the group of patients with high ICP versus $617.6 \mathrm{pg} / \mathrm{mL} \cdot \mathrm{hr}$ in the patients with low ICP (Fig. 1A). Patients with high ICP presented with higher caspase-1 levels in CSF, especially on days 2 and 3 (Table 2). However, we did not detect such a correlation in serum samples (Table 3, Fig. 1B).

\section{High Caspase-1 Levels Are Present in the CSF of Patients With TBI Who Have Unfavorable Outcomes}

Using the sliding dichotomy approach, which relates outcome to baseline prognostic risk, 4 patients presented with favorable outcome in this cohort of patients with TBI. The AUC value of caspase in CSF during the 5-day period 

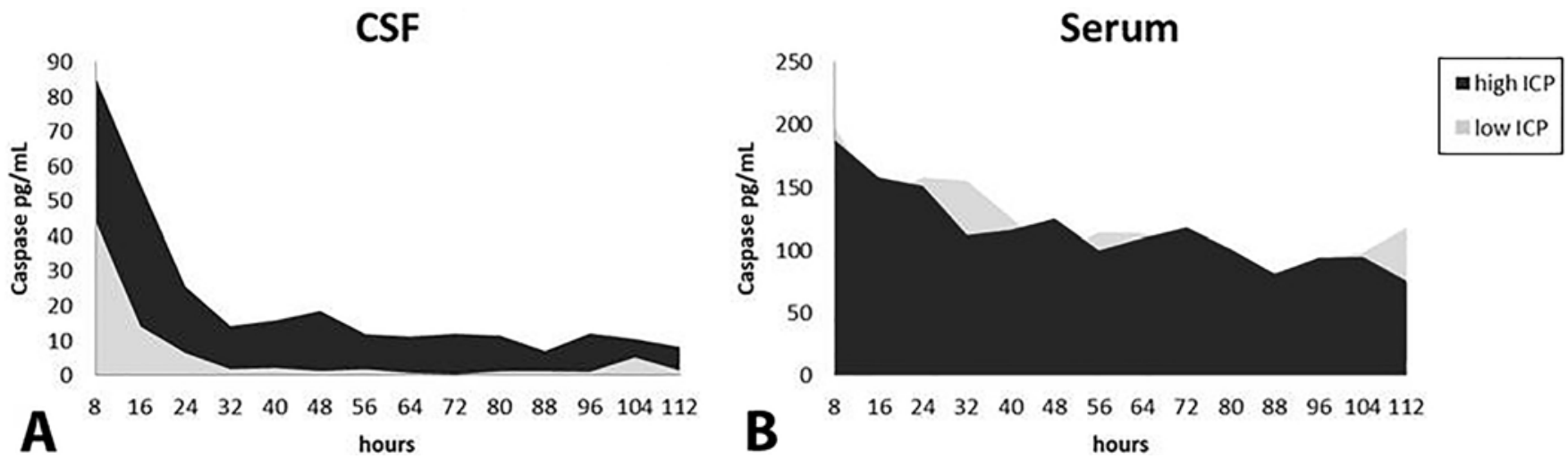

FIG. 1. Temporal profile of caspase-1 in CSF and serum in TBI patients with low and high ICP. AUC for caspase-1 protein levels in CSF (A) and serum (B) during the first 5 days after TBI in patients with low ICP and in those with high ICP.

was $1918.9 \mathrm{pg} / \mathrm{mL} \cdot \mathrm{hr}$ in the group of patients with unfavorable outcome versus $924.5 \mathrm{pg} / \mathrm{mL} \cdot \mathrm{hr}$ in the patients with favorable outcome (Fig. 2A). The protein levels of caspase-1 in CSF were higher in patients with unfavorable outcomes during the first 4 days after TBI, but these differences did not reach statistical significance (Table 4). However, the protein levels of caspase- 1 in serum were similar in both groups regardless of the outcome (Table 5, Fig. 2B).

\section{The Trend of Caspase-1 Protein Levels in CSF and Not the Absolute Value Is Associated With Better Outcomes}

We also looked for patients with 2 consecutive increases in protein levels. Of the 21 patients, 9 presented with 2 consecutive increases in protein levels of caspase- 1 in CSF. All 9 patients had a poor outcome. Of the 11 patients who did not present with this consecutive increase in the protein levels of caspase- 1 in CSF, only $54 \%$ had a poor outcome and $46 \%$ had a good outcome.

\section{Discussion}

The main findings of this prospective and observational study in this cohort of patients with moderate and severe TBI are the following: first, caspase- 1 is elevated in the CSF of patients with a TBI and high ICP, especially on the 2nd and 3rd day after TBI; second, caspase-1 protein levels in CSF are also higher in patients with poor outcome during the first 96 hours after TBI; third, the trend of caspase-1, and not the absolute value, seems to correlate better with outcome.

TABLE 2. Daily values of caspase-1 in CSF of patients with low or high ICP

\begin{tabular}{crrrrr}
\hline CSF Caspase-1 & Day 1 & Day 2* & Day 3† & Day 4 & Day 5 \\
\hline Low ICP & 19.2 & 1.8 & 1.0 & 1.2 & 1.6 \\
\hline High ICP & 25.8 & 19.7 & 13.9 & 10.2 & 16.0 \\
\hline
\end{tabular}

Seven patients presented with low ICP and 14 with high ICP. Protein concentrations represent the daily median value of caspase-1 in $\mathrm{pg} / \mathrm{mL}$.

${ }^{*} p=0.06$ (Bonferroni correction).

$\dagger p=0.05$ (Bonferroni correction).
Our results are in agreement with previously published studies in which we have described that the inflammasome proteins, specifically ASC, caspase-1, and NLRP-1, were significantly higher in the CSF of patients with poor outcome. ${ }^{14}$ Nevertheless, in those studies the expression of the inflammasome proteins was analyzed by immunoblotting. In previous studies, the levels were not quantified and the sample frequency was not predefined. In this new study, we have measured the concentrations of caspase-1 and ASC by using commercially available ELISAs, and we also predetermined the sample frequency. Nevertheless, ASC protein levels could not be determined in many serum or CSF samples, and this could be due to the technique used in this study to measure the inflammasome proteins. Recently, in a different cohort of patients we carried out biomarker analyses of inflammasome proteins by using a different technology relying on microfluidics for protein analysis. In that study, we showed that caspase-1 and ASC are promising biomarkers of TBI with AUC values as high as 0.93 and 0.90 , respectively. ${ }^{15}$

In this study we have described the temporal profile of caspase-1. To assess the temporal profile of a new biomarker is challenging but necessary to provide this kind of molecular-level information about the ongoing pathobiological changes after TBI. ${ }^{17}$ To know this information is of paramount importance in planning specific intervention and in assessing individual patient responses. ${ }^{18}$ Interestingly, in this study not only the absolute value of caspase- 1 but also the trend of its value seems to be relevant for the outcome, similarly to microdialysis, ${ }^{19}$ where it is well known that for glucose or the lactate/pyruvate ratio the trend is as important or possibly more important than point values or threshold values.

TABLE 3. Daily values of caspase-1 in serum of patients with low or high ICP

\begin{tabular}{cccccc}
\hline Serum Caspase-1 & Day 1 & Day 2 & Day 3 & Day 4 & Day 5 \\
\hline Low ICP & 163.6 & 130.7 & 121.5 & 83.0 & 84.0 \\
\hline High ICP & 162.3 & 122.8 & 119.7 & 93.5 & 86.9 \\
\hline
\end{tabular}

Seven patients presented with low ICP and 14 with high ICP. Protein concentrations represent the daily median value of caspase- 1 in $\mathrm{pg} / \mathrm{mL}$. 

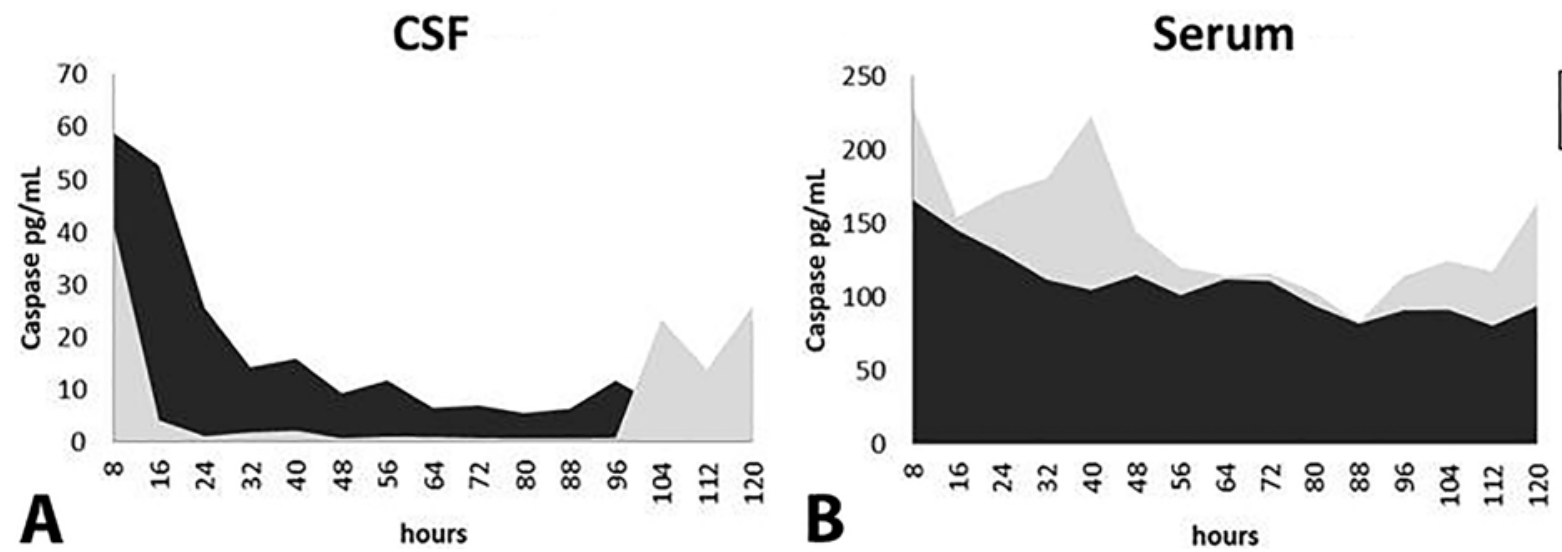

FIG. 2. Temporal profile of caspase-1 in CSF and serum in TBI patients with favorable and unfavorable outcome. AUC for caspase-1 expression in CSF (A) and serum (B) during the first 5 days after TBI in patients with favorable outcomes and in those with unfavorable outcomes.

There are strengths and weaknesses for the use of CSF or blood-based biomarkers for TBI. ${ }^{20} \mathrm{CSF}$ biomarkers may directly reflect CNS composition. However, CSF sampling requires an invasive procedure such as lumbar puncture or external ventricular drain placement. On the other hand, blood biomarkers are less invasive, but may not closely reflect brain parenchymal content. Nevertheless, the serial nature of sampling warrants consideration for developing blood-based biomarkers rather than CSF as diagnostic and prognostic tools. ${ }^{21}$

To identify biomarkers that can be measured in the acute period and that may be useful to guide pharmacological interventions is a challenge. Some of the recommendations made by experts in this regard include the following: ${ }^{21}$ perform a high initial sampling frequency to map trajectories over time; try to correlate with other monitoring techniques, such as imaging or multimodal monitoring (ICP, cerebral perfusion pressure, metabolism); identify and study TBI cohorts that are clinically definable, such as patients with TBI in the NICU; analyze these proteins in a blinded fashion so as not to influence treatment strategies; and use a well-validated assay, preferably with industrial-level calibration. In this study we have tried to adopt as many of these recommendations as possible.

Nevertheless this study has limitations. As a result of the varying injury circumstances, admission to the ICU, and subsequent clinical progress, patients in this study were sampled at different time periods, especially those

TABLE 4. Daily protein concentration of caspase-1 in CSF of patients with favorable and unfavorable outcome according to the sliding dichotomy approach

\begin{tabular}{cccccc}
\hline CSF Caspase-1 & Day 1 & Day 2 & Day 3 & Day 4 & Day 5 \\
\hline Favorable & 13.8 & 2.5 & 0.84 & 0.70 & 25.6 \\
\hline Unfavorable & 24.5 & 19.0 & 9.2 & 8.7 & 15.2 \\
\hline
\end{tabular}

Four patients presented with favorable outcome and 17 with unfavorable outcome. Protein concentrations represent the daily median value of caspase-1 in $\mathrm{pg} / \mathrm{mL}$. in the first sample. The initial intracranial injury, potential extracranial trauma as well as injury progression, and the occurrence of secondary injuries will influence the biomarker's temporal profile. Furthermore, several factors may influence ICP, such as surgery or the decompressive craniectomy that was performed in 5 cases. Undoubtedly, all these factors have influenced the results. In addition, despite using the sliding dichotomy approach, we had to dichotomize the outcome due to the small sample size of the study. Inflammasome production is a dynamic process and rises and falls over time; thus, expressing inflammasome concentrations as an average every 8 hours, as seen in Figs. 1 and 2, clearly masks the time course. This makes it difficult to know why late variations in inflammasome levels were produced. Therefore, it is unknown what sampling frequency is needed to capture all this information. We collected 3 serum and CSF samples per day for 5 days, although this frequency is clearly not adequate to study all the possible variations in inflammasome levels. Finally, different patterns of biomarker release imply that different patterns of structural damage involve various pathophysiological mechanisms and may require different therapeutic approaches. For this reason, in the future we should try to find associations between the levels of the inflammasomes and other monitoring techniques, especially the CT scan. In addition, because some patients with TBI tend to develop cognitive impairment, future studies will look into biomarkers that can differentiate TBI patients with and without cognitive impairment.

TABLE 5. Daily protein concentration of caspase-1 in serum of patients with favorable and unfavorable outcome according to the sliding dichotomy approach

\begin{tabular}{cccccc}
\hline Serum Caspase-1 & Day 1 & Day 2 & Day 3 & Day 4 & Day 5 \\
\hline Favorable & 163.6 & 200.0 & 123.7 & 92.7 & 124.3 \\
\hline Unfavorable & 163.3 & 121.1 & 111.1 & 86.5 & 85.7 \\
\hline
\end{tabular}

Four patients presented with favorable outcome and 17 with unfavorable outcome. Protein concentrations represent the daily median value of caspase- 1 in $\mathrm{pg} / \mathrm{mL}$. 


\section{Conclusions}

Taken together, in this cohort of patients with TBI who were admitted to the NICU we show that the inflammasome protein caspase-1 is increased in the CSF of patients with high ICP, especially on days 2 and 3 after TBI. Also the protein levels of caspase-1 in CSF were higher in patients with poor outcome during the first 96 hours after TBI. Moreover, not only the absolute value of caspase- 1 in CSF but also its trend is associated with poor outcomes.

\section{Acknowledgments}

This work was supported by a public grant from the Fondo de Investigación Sanitaria (FISPI16/00737).

\section{References}

1. Maas AIR, Menon DK, Adelson PD, et al. Traumatic brain injury: integrated approaches to improve prevention, clinical care, and research. Lancet Neurol. 2017;16(12):987-1048.

2. de Rivero Vaccari JP, Brand F III, Adamczak S, et al. Exosome-mediated inflammasome signaling after central nervous system injury. J Neurochem. 2016;136(suppl 1):39-48.

3. Kerr N, García-Contreras M, Abbassi S, et al. Inflammasome proteins in serum and serum-derived extracellular vesicles as biomarkers of stroke. Front Mol Neurosci. 2018;11:309.

4. Keane RW, Dietrich WD, de Rivero Vaccari JP. Inflammasome proteins as biomarkers of multiple sclerosis. Front $\mathrm{Neu}$ rol. 2018;9:135.

5. Syed SA, Beurel E, Loewenstein DA, et al. Defective inflammatory pathways in never-treated depressed patients are associated with poor treatment response. Neuron. 2018;99(5):914924.e3.

6. Abulafia DP, de Rivero Vaccari JP, Lozano JD, et al. Inhibition of the inflammasome complex reduces the inflammatory response after thromboembolic stroke in mice. J Cereb Blood Flow Metab. 2009;29(3):534-544.

7. de Rivero Vaccari JP, Dietrich WD, Keane RW. Activation and regulation of cellular inflammasomes: gaps in our knowledge for central nervous system injury. J Cereb Blood Flow Metab. 2014;34(3):369-375.

8. de Rivero Vaccari JP, Lotocki G, Marcillo AE, et al. A molecular platform in neurons regulates inflammation after spinal cord injury. J Neurosci. 2008;28(13):3404-3414.

9. Kawata K, Tierney R, Langford D. Blood and cerebrospinal fluid biomarkers. Handb Clin Neurol. 2018;158:217-233.

10. Davis BK, Wen H, Ting JP. The inflammasome NLRs in immunity, inflammation, and associated diseases. Annu Rev Immunol. 2011;29:707-735.

11. Kigerl KA, de Rivero Vaccari JP, Dietrich WD, et al. Pattern recognition receptors and central nervous system repair. Exp Neurol. 2014;258:5-16.

12. de Rivero Vaccari JP, Lotocki G, Alonso OF, et al. Therapeutic neutralization of the NLRP1 inflammasome reduces the innate immune response and improves histopathology after traumatic brain injury. J Cereb Blood Flow Metab. 2009;29(7):1251-1261.

13. Xu X, Yin D, Ren H, et al. Selective NLRP3 inflammasome inhibitor reduces neuroinflammation and improves long-term neurological outcomes in a murine model of traumatic brain injury. Neurobiol Dis. 2018;117:15-27.
14. Adamczak S, Dale G, de Rivero Vaccari JP, et al. Inflammasome proteins in cerebrospinal fluid of brain-injured patients as biomarkers of functional outcome: clinical article. $\mathrm{J} \mathrm{Neu}$ rosurg. 2012;117(6):1119-1125.

15. Kerr N, Lee SW, Perez-Barcena J, et al. Inflammasome proteins as biomarkers of traumatic brain injury. PLoS One. 2018;13(12):e0210128.

16. Wright DW, Yeatts SD, Silbergleit R, et al. Very early administration of progesterone for acute traumatic brain injury. $N$ Engl J Med. 2014;371(26):2457-2466.

17. Mondello S, Papa L, Buki A, et al. Neuronal and glial markers are differently associated with computed tomography findings and outcome in patients with severe traumatic brain injury: a case control study. Crit Care. 2011;15(3):R156.

18. Ismael S, Nasoohi S, Ishrat T. MCC950, the selective inhibitor of nucleotide oligomerization domain-like receptor protein-3 inflammasome, protects mice against traumatic brain injury. J Neurotrauma. 2018;35(11):1294-1303.

19. Hutchinson PJ, Jalloh I, Helmy A, et al. Consensus statement from the 2014 International Microdialysis Forum. Intensive Care Med. 2015;41(9):1517-1528.

20. Agoston DV, Shutes-David A, Peskind ER. Biofluid biomarkers of traumatic brain injury. Brain Inj. 2017;31(9):1195-1203.

21. Thelin EP, Zeiler FA, Ercole A, et al. Serial sampling of serum protein biomarkers for monitoring human traumatic brain injury dynamics: a systematic review. Front Neurol. 2017;8:300.

22. de Rivero Vaccari JP, Dietrich WD, Keane RW. Therapeutics targeting the inflammasome after central nervous system injury. Transl Res. 2016;167(1):35-45.

\section{Disclosures}

Dr. de Rivero Vaccari is a cofounder and managing member of InflamaCORE, LLC, and has licensed patents on inflammasome proteins as biomarkers of injury and disease as well as on targeting inflammasome proteins for therapeutic purposes. He is a scientific advisory board member of ZyVersa Therapeutics.

\section{Author Contributions}

Conception and design: Pérez-Bárcena, de Rivero Vaccari. Acquisition of data: Pérez-Bárcena, Crespí, Llompart-Pou, Salazar, Goliney, Ibañez. Analysis and interpretation of data: Pérez-Bárcena, Crespí, Frontera, Ibañez, Bullock, de Rivero Vaccari. Drafting the article: Pérez-Bárcena. Critically revising the article: Crespí, Frontera, Llompart-Pou, Salazar, Goliney, Ibañez, Bullock, de Rivero Vaccari. Reviewed submitted version of manuscript: all authors. Approved the final version of the manuscript on behalf of all authors: Pérez-Bárcena. Statistical analysis: Frontera. Administrative/technical/material support: Crespí.

\section{Correspondence}

Juan Pablo de Rivero Vaccari: Lois Pope LIFE Center, Miami, FL.jderivero@med.miami.edu. 